\title{
Tensile bond strength of a lithium-disilicate pressed glass ceramic to dentin of different surface treatments
}

\author{
Mustafa ZORTUK ${ }^{1}$, Kerem KILIC ${ }^{1}$, Aysegul Guleryuz GURBULAK ${ }^{1}$, Bulent KESIM¹ and Sadullah UCTASLI ${ }^{2}$ \\ ${ }^{1}$ Department of Prosthetic Dentistry, Faculty of Dentistry, Erciyes University, Kayseri, Turkey \\ ${ }^{2}$ Department of Prosthetic Dentistry, Faculty of Dentistry, Ankara University, Ankara, Turkey \\ Corresponding author, Mustafa ZORTUK; E-mail: mzortuk@erciyes.edu.tr
}

\begin{abstract}
The effects of desensitizer, disinfectant, saliva, blood, and hydrogen peroxide on the tensile bond strength between adhesive and ceramic as well as between adhesive and dentin were examined. Sixty $7 \times 3 \mathrm{~mm}$ pressed ceramic discs of IPS e.max were fabricated and randomly assigned to six groups of different dentin surface treatments (control, desensitizer, disinfectant, saliva, blood, and hydrogen peroxide). Representative samples of fractured specimens were observed by SEM (scanning electron microscopy). There were significant differences between the control group and saliva, blood, and hydrogen peroxide groups $(p<0.05)$. However, there were no significant differences between any other dentin surface treatment groups $(p>0.05)$. Results of this study suggested that only saliva, blood, and hydrogen peroxide influenced the tensile bond strength between dentin and ceramic.
\end{abstract}

Keywords: Dental ceramics, Adhesive cements, Tensile strength

\section{INTRODUCTION}

It has becoming increasing popular for all-ceramic dental restorations to combine an esthetic but weak porcelain veneer with a strong ceramic core. Veneering porcelains typically consist of a glass and a crystalline phase of fluoroapatite, aluminum oxide, or leucite. Veneering a lithium disilicate, aluminum oxide, or zirconium oxide core with glass allows dental technicians to customize restorations in terms of form and esthetics. The success of these systems hinges on preventing failures between the restorative material and the dental substrate ${ }^{1-5)}$.

Notably, good adhesion between the tooth and restorative material is recognized to play a pivotal role in the success of dental restorations ${ }^{1,6}$. When bonding ceramic to tooth substrates, it is important to ensure optimal bond strength at two different interfaces namely, the dentin-adhesive and ceramic-adhesive interfaces, because these two interfaces determine the overall, final bond strength of the restoration ${ }^{7}$. Moreover, durable bonding between dentin and adhesives is important for avoiding detachment of restorations and for preventing microleakage, secondary dental caries, and tooth fractures ${ }^{10)}$. At the ceramicadhesive interface, in vitro studies have shown that reliable bonding could be achieved by acid-etching the ceramic surface and applying a silane coupling agent ${ }^{8,9)}$. At dentin-adhesive interfaces, it has been shown that reliable bonding could be achieved by dentin surface treatments. However, the dentin-adhesive bond is not as strong as that between ceramic and dentin because dentin is biologically active and complex ${ }^{11,12)}$.

On factors that may affect the chemical interaction between restorative materials and dentin, and perhaps even the sealing and bonding properties of luting agents, they include the ingredients of desensitizers, antibacterial solutions, and hydrogen peroxide. Besides, saliva and blood contamination may also create a thin film on the dentin surface that hinders adhesive penetration into the dentinal tubules ${ }^{10,13,14)}$. In the wake of these concerns, the present study evaluated the effects of various dentin surface treatments (desensitizer, disinfectant, saliva, blood, hydrogen peroxide, no treatment [wet dentin]) on the tensile bond strengths of the adhesive-dentin interface and adhesive-ceramic (lithium disilicate glass ceramic) interface. The null hypothesis was that the tensile bond strengths of both interfaces would be similar for all dentin surface conditions.

\section{MATERIALS AND METHODS}

The materials used in this study are presented in Table 1.

\section{Ceramic disc preparation}

Sixty $7 \times 3 \mathrm{~mm}$ pressed lithium disilicate glass ceramic discs of IPS e.max (Ivoclar Vivadent AG, Schaan, Liechtenstein) were fabricated using the lost wax technique, and ingots were injected into an EP 600 furnace (Ivoclar Vivadent AG, Schaan, Liechtenstein).

Disc surfaces were ground with 220-, 360-, and 600 -grit silicon carbide sandpapers to standardize the bonding surfaces. Ground ceramic discs were airabraded with 50- $\mu \mathrm{m} \mathrm{Al}_{2} \mathrm{O}_{3}$ particles (Korox, Bego, Bremen, Germany) for 14 seconds from a distance of approximately $10 \mathrm{~mm}$ at $400 \mathrm{kPa}$ with a sandblasting device (Ar-Ge Dental, Denizli, Turkey). The discs were then cleaned in distilled water for 10 minutes in an ultrasonic bath (Healthsonics, Livermore, California, USA) to ensure contaminant-free surfaces. The bonding surfaces of the ceramic discs were etched with 37\% phosphoric acid (K-Etchant Gel, Kuraray, Tokyo, Japan) for 5 seconds, rinsed for 30 seconds with a 
Table 1 Materials used in the study

\begin{tabular}{|c|c|c|c|}
\hline Name & Manufacturer & Ingredients & Lot number \\
\hline IPS e.max & $\begin{array}{l}\text { Ivoclar Vivadent, Schaan, } \\
\text { Liechtenstein }\end{array}$ & Lithium disilicate glass ceramic & H36067 \\
\hline $\begin{array}{l}\text { Clearfil Esthetic } \\
\text { Cement }\end{array}$ & Kuraray, Tokyo, Japan & $\begin{array}{l}\text { Paste A: Bis-GMA, TEGDMA, } \\
\text { methacrylate monomers, silanated glass } \\
\text { filler. } \\
\text { Paste B: Bis-GMA, TEGDMA, } \\
\text { methacrylate monomers, silanated glass } \\
\text { filler, colloidal silica, benzoyl peroxide, } \\
\text { dl-camphorquinone. }\end{array}$ & 08000101126 \\
\hline $\begin{array}{l}\text { Clinpro White } \\
\text { Varnish } \\
\text { desensitizer }\end{array}$ & $\begin{array}{l}\text { 3M ESPE, St. Paul, MN, } \\
\text { USA }\end{array}$ & Sodium fluoride ions, modified resins & M12190 \\
\hline Farhex & $\begin{array}{l}\text { Santa Farma, Istanbul, } \\
\text { Turkey }\end{array}$ & $\begin{array}{l}\text { Chlorhexidine gluconate, benzydamine } \\
\text { hydrochloride, aspartame, ethyl alcohol }\end{array}$ & 1808 \\
\hline
\end{tabular}

water spray, air-dried, and then silanated with a silane coupling agent (Clearfil Ceramic Primer, Kuraray, Tokyo, Japan) for 60 seconds.

\section{Tooth preparation}

Sixty caries-free unrestored human third molars, which had been stored in $0.5 \%$ Cloramin-T solution at $4^{\circ} \mathrm{C}$ for up to 1 month after extraction, were selected as tooth specimens. Soft tissues were removed with a scaler (H6/H7 Scaler, Hu-Friedy, Chicago, USA). After cleaning the teeth with pumice, each tooth was embedded in an autopolymerizing acrylic resin (Palapress Vario, Heraeus Kulzer GmbH, Wehrheim, Germany) in a cylindrical plastic mold of $20 \mathrm{~mm}$ height and $20 \mathrm{~mm}$ diameter. Enamel was removed by cutting off the crown horizontally at the middle, exactly at the top of the pulp chamber, using a low-speed diamond saw (Minitom, Struers, Copenhagen, Denmark). Deep dentin was chosen in this study to favor the diffusion of adhesive into the demineralized dentin. This is because the number of tubules in coronal dentin increases significantly from the middle to the deep layer - nearest to the pulp, thus providing the best conditions for resin monomer infiltration. A standard smear layer was produced by wet-sanding the dentin surface with 600-grit silicon carbide sandpaper for 40 seconds.

\section{Experimental design}

The 60 prepared specimens were randomly assigned to six groups of different dentin surface treatments $(n=10$ each):

Group 1 (control): Wet dentin. No contaminant was added.

Group 2: Clinpro White Varnish desensitizer (3M ESPE, St. Paul, MN, USA) was applied according to manufacturer's instructions. Dentin surface was rinsed with a water spray for 10 seconds and blotted with absorbent paper.

Group 3: Farhex (2\%, $1 \mathrm{~mL})$ disinfectant solution was applied for 20 seconds. After rinsing with a water spray for 10 seconds, excess water was removed with absorbent paper.

Group 4: Saliva was applied with a microbrush for 20 seconds, rinsed for 10 seconds, and blotted with absorbent paper.

Group 5: Fresh capillary human blood (supply from a single donor) was applied with a micropipette for 20 seconds, rinsed for 10 seconds, and blotted with absorbent paper.

Group 6: Hydrogen peroxide $\left(\mathrm{H}_{2} \mathrm{O}_{2}\right)$ applied with a micropipette for 20 seconds, rinsed for 10 seconds, and blotted with absorbent paper.

\section{Bonding procedures}

A dual-polymerizing resin cement was used (Clearfil Esthetic Cement, Kuraray, Tokyo, Japan) as the adhesive. Equal amounts of ED Primer II Liquids A and $\mathrm{B}$ were mixed and applied to the dentin surface for 30 seconds, and then the surface was thoroughly airdried. Clearfil Esthetic Cement pastes A and B were mixed and then applied to the ceramic surfaces using a dispenser syringe. A special loading device was designed to apply a constant load of $9.2 \mathrm{~N}$ to the ceramic discs. This load was used to create a uniform resin luting layer of approximately $100 \mu \mathrm{m}$, so as to simulate the film thickness employed for all-ceramic crowns. Initial light curing was performed for 10 seconds. Excess cement was removed using a dental probe. The luting agent was polymerized from each direction (mesial, distal, buccal, lingual, occlusal) with an LED curing device for 40 seconds (light intensity: $-1,000 \mathrm{~mW} / \mathrm{cm}^{2}$; Elipar FreeLight 2 LED Curing Light, 3M ESPE, MN, USA).

\section{Tensile bond strength test}

Following storage in distilled water at $37^{\circ} \mathrm{C}$ for 24 hours, the specimens were thermocycled for 6,000 cycles between $5 \pm 2^{\circ} \mathrm{C}$ and $55 \pm 2^{\circ} \mathrm{C}$, with a dwell time of 20 seconds and a transfer time of 5 seconds. The thermocycling process was completed in 4.5 days. If a spontaneous interfacial debonding occurred during the 
thermocycling process, the corresponding bond strength was recorded as $0 \mathrm{MPa}$.

After the thermocycling process, each specimen was mounted on the lower fixture of a universal testing machine (Model 6022, Instron Corp, Norwood, USA) and an orthodontic wire connected to the upper fixture. Bonded dentin ceramic specimens were then subjected to a tensile force at a crosshead speed of $2 \mathrm{~mm} / \mathrm{min}$ until decementation occurred. Tensile bond strengths were calculated using the following formula:

Tensile bond strength $(\mathrm{MPa})=\mathrm{P} / \mathrm{A}$

where $\mathrm{P}$ is the maximum force $(\mathrm{N})$ and $\mathrm{A}$ is the interfacial area $\left(\mathrm{mm}^{2}\right)$.

Stereomicroscope and scanning electron microscope (SEM) examination

After tensile bond strength testing, the dentin surfaces of the debonded specimens were examined with a stereomicroscope (Wild M3B, Heerbrugg, Switzerland) at $25 \times$ magnification to identify bond failure modes. Failure modes were classified as follows:

- Adhesive failure at dentin-resin interface (A/D$\mathrm{R})$ : Dentinal tubules were observed to be open and no broken resin was apparent on the intertubular dentin surface;

- Adhesive failure at resin-ceramic interface (A/RC); and

- Cohesive failure within resin $(\mathrm{C} / \mathrm{R})$.

For SEM analysis, two specimens were randomly selected from each group for this purpose. The debonded specimens from each group were sputter coated (Bal-Tec SCD 050 Sputter Coater, Bal-Tec AG, Balzers, Liechtenstein) with gold and observed with a scanning electron microscope (LEO 440, Leica-Zeiss, Cambridge, UK).

\section{Statistical analyses}

All data sets were subjected to normality tests using the Kolmogorov-Smirnov method, and data were presented as medians and 25th and 75th percentiles (for skewed data). The nonparametric Kruskal-Wallis test was used to compare the groups, and Dunn's multiple comparison test was used to evaluate the subgroups. $p$ values of $<0.05$ were deemed statistically significant. All analyses were performed using a statistical package for scientists, SigmaStat (Aspire Software International, Washington, USA), Windows version 3.10 .

\section{RESULTS}

Specimens which debonded during thermocycling were added to statistical analysis as $0 \mathrm{MPa}$. Medians and 25/75 percentiles of the measured tensile bond strengths are shown in Table 2. Kruskal-Wallis test revealed significant differences between the groups $(p<0.05)$, and Table 3 presents the results of Dunn's multiple comparison test. There were significant differences between Groups 1 and $4(p<0.05)$, between Groups 1 and $5(p<0.05)$, and between Groups 1 and 6
Table 2 Medians and 25/75 percentiles of the tensile bond strength $(\mathrm{MPa})$ of dentin surface treatment groups

\begin{tabular}{lcccc}
\hline Groups & $n$ & Median & $25 \%$ & $75 \%$ \\
\hline Group 1 & 10 & 22.61 & 19.42 & 28.74 \\
Group 2 & 10 & 16.87 & 10.30 & 28.25 \\
Group 3 & 10 & 8.82 & 6.28 & 14.72 \\
Group 4 & 10 & 2.35 & 0 & 7.46 \\
Group 5 & 10 & 1.71 & 0 & 19.52 \\
Group 6 & 10 & 4.36 & 0 & 10.01 \\
\hline
\end{tabular}

Table 3 Comparison ( $p$ values) between dentin surface treatment groups

\begin{tabular}{lc}
\hline Dunn's multiple comparison test & $p$ values \\
\hline Control/desensitizer & $>0.05$ \\
Control/chlorhexidin gluconate & $>0.05$ \\
Control/saliva & $<0.05$ \\
Control/blood & $<0.05$ \\
Control/ $\mathrm{H}_{2} \mathrm{O}_{2}$ & $<0.05$ \\
\hline
\end{tabular}

Table 4 Failure mode data

\begin{tabular}{lcccc}
\hline Groups & $n$ & $\mathrm{~A} / \mathrm{D}-\mathrm{R}$ & $\mathrm{C} / \mathrm{R}$ & $\mathrm{A} / \mathrm{R}-\mathrm{C}$ \\
\hline Group 1 & 10 & 3 & 6 & 1 \\
Group 2 & 10 & 5 & 4 & 1 \\
Group 3 & 10 & 7 & 3 & - \\
Group 4 & 10 & 8 & 2 & - \\
Group 5 & 10 & 9 & 1 & - \\
Group 6 & 10 & 10 & - & - \\
\hline
\end{tabular}

A/D-R: Adhesive failure at resin-dentin interface; $\mathrm{C} / \mathrm{R}$ : Cohesive failure of resin; A/R-C: Adhesive failure at resin-ceramic interface.

$(p<0.05)$. There were no significant differences between any other groups.

Failure modes of the six surface treatment groups as identified using a stereomicroscope and the number of occurrences thereof are shown in Table 4 . In the control group, there were three occurrences of adhesive failure at the adhesive-dentin interface, but it varied between five and 10 occurrences in the other surface treatment groups.

The SEM images of representative fractured 


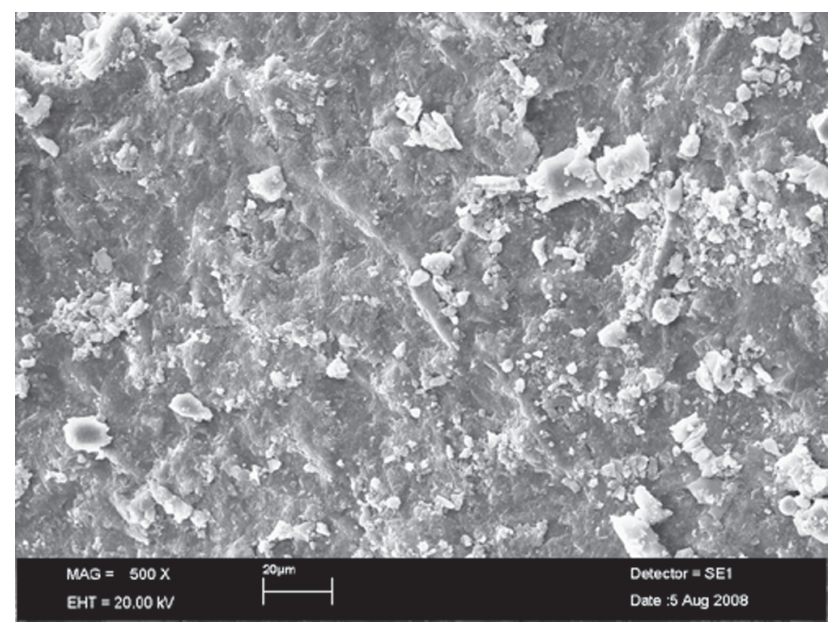

Fig. 1 No contaminant was applied in the control group. SEM image of a smear layer covering the dentin surface (A/R-C). Magnification: 500×.

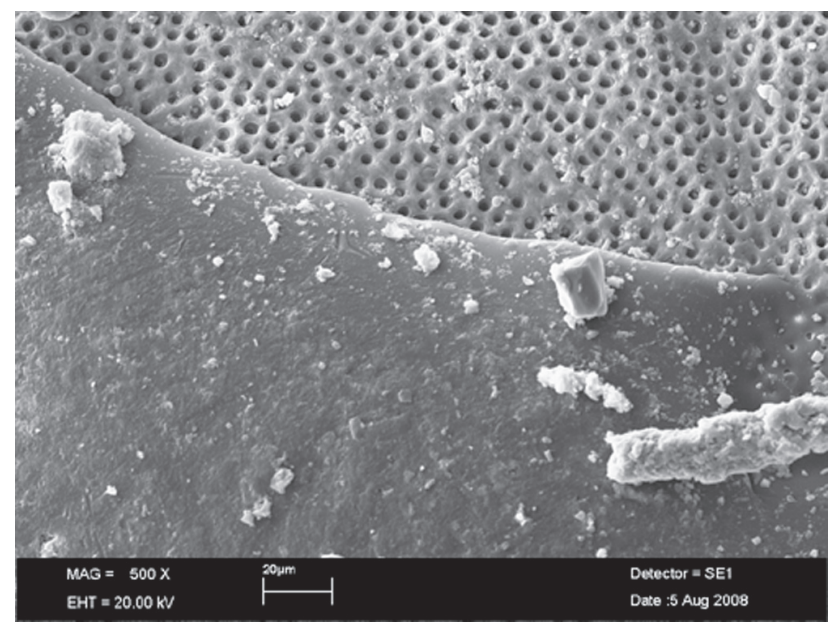

Fig. 2 SEM image of dentin surface treated with desensitizer. Smear layer was partially removed, and both residual resin and tubular orifices were observed (C/R). Magnification: 500×.

specimens from the six dentin surface treatment groups are shown in Figs. 1-6. In the control group and Group 3 (Figs. 1 and 3 respectively), resin covered the dentin surface and their failure modes were determined as $\mathrm{A} /$ R-C adhesive failure. In Group 2 (Fig. 2), both residual resin and tubular orifices were observed, and the failure mode of specimen was determined as $\mathrm{C} / \mathrm{R}$ cohesive failure. In Groups 4, 5, and 6 (Figs. 4, 5, and 6 respectively), the tubular orifices were observed to be open over the bonding area and the failure modes of specimens were determined as $\mathrm{A} / \mathrm{D}-\mathrm{R}$ adhesive failure.

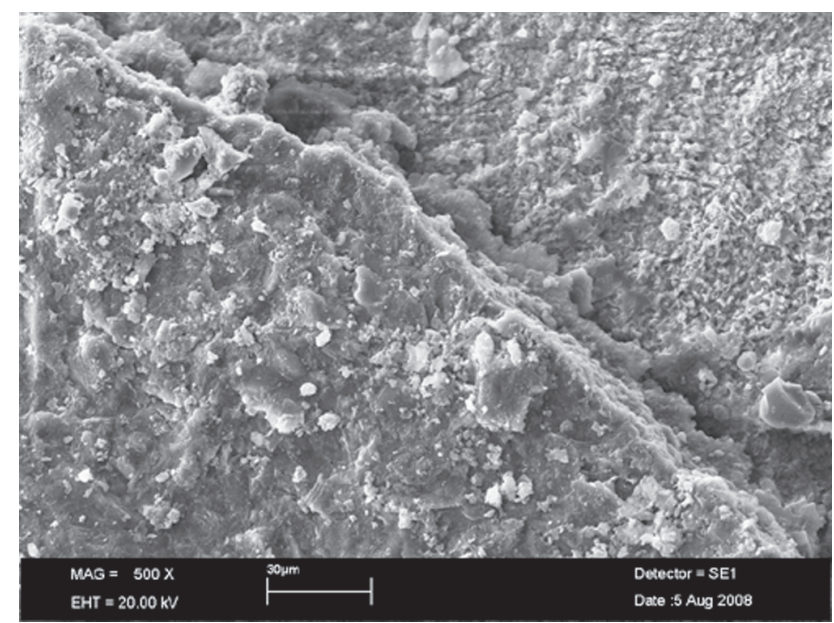

Fig. 3 SEM image of dentin surface treated with chlorhexidine gluconate. Smear layer covered the dentin surface (A/R-C). Magnification: 500×.

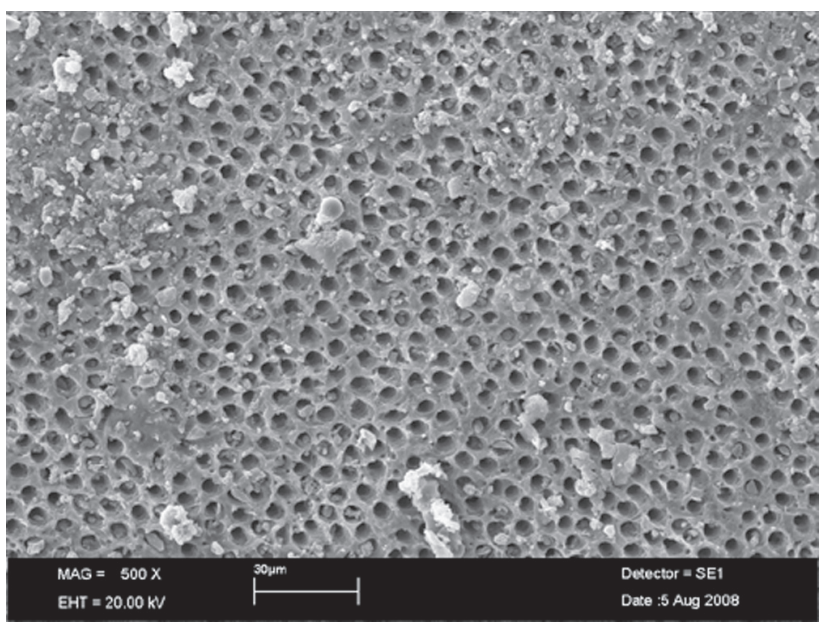

Fig. 4 SEM image of dentin surface contaminated with saliva. Smear layer was removed, and the tubular orifices were observed to be open all over the bonding area (A/D-R). Magnification: 500×.

\section{DISCUSSION}

A durable and predictable bond strength between dental materials and tooth substrates is critical to clinical success ${ }^{15)}$. In this respect, it is very important to detect and remove contaminants from the dentin surface to ensure the long-term success of dental restorations ${ }^{16)}$. Thus, in this study, the effects of desensitizer, disinfectant, saliva, blood, and hydrogen peroxide contamination on adhesive-dentin bonding were investigated by simulating a clinical try-in procedure. The results obtained in this study did not support the hypothesis that the tensile bond strengths of both adhesive-dentin and adhesive-ceramic interfaces 


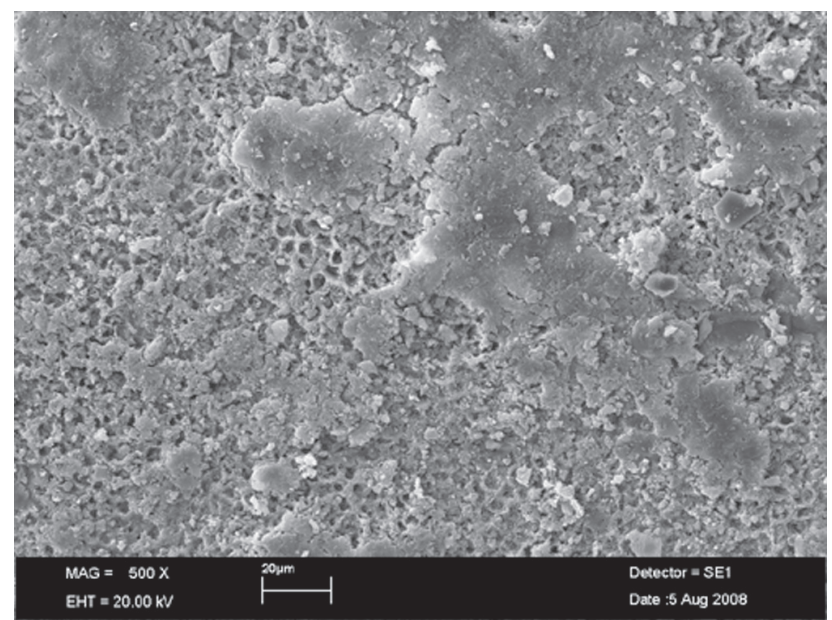

Fig. 5 SEM image of dentin surface contaminated with human blood. Smear layer was removed, and the tubular orifices were observed to be open all over the bonding area (A/D-R). Magnification: 500×.

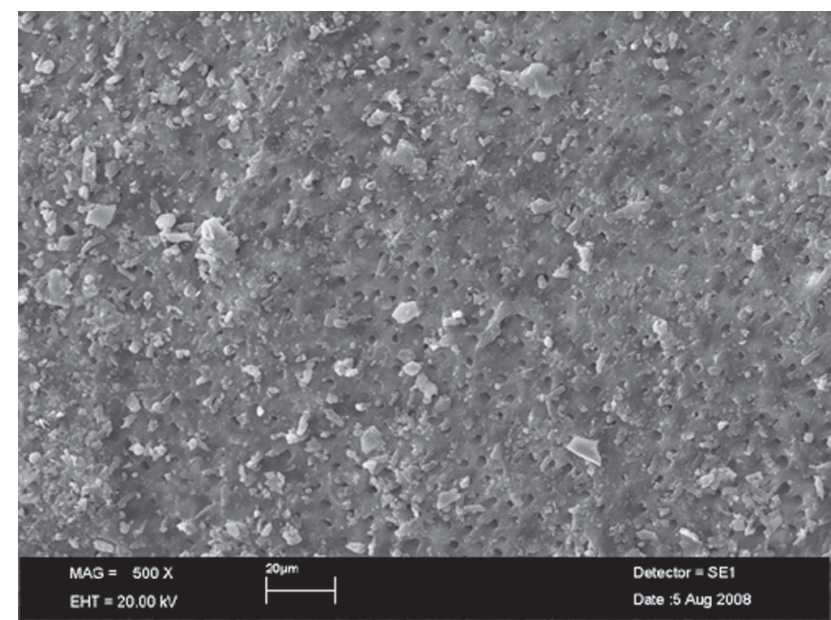

Fig. 6 SEM image of dentin surface treated with $\mathrm{H}_{2} \mathrm{O}_{2}$. Smear layer was removed, and the tubular orifices were observed to be open all over the bonding area (A/D-R). Magnification: 500×.

treated with chlorhexidine gluconate disinfectant. After filling a cavity, bacteria that remain behind may cause secondary caries under the restoration and further damage the tooth ${ }^{22}$. For this reason, chlorhexidine gluconate is widely used as an antimicrobial agent for disinfection before the placement of restorations. Chlorhexidine gluconate, which binds to the amino acids in the dentin and which is able to kill bacteria for several hours, makes it an effective antimicrobial agent ${ }^{23)}$. In this study, our results were consistent with those of previous studies which showed that chlorhexidine gluconate application prior to acid-etching had no adverse effect on both adhesive-ceramic and adhesive-dentin interfaces ${ }^{24,25)}$. Moreover, SEM observation seemed to suggest that chlorhexidine gluconate application might also lead to better preservation of naked collagen fibrils as they were sealed by a layer of adhesive resin (Fig. 3) ${ }^{13)}$.

However, the benefit(s) of using chlorhexidine gluconate should be further weighed and examined against the side effects which limit its widespread use, such as brown staining of the teeth, an increase in calculus deposits, and difficulty in completely masking its taste when used as a rinse. Despite these concerns and drawbacks, using chlorhexidine gluconate to complement restorative procedures does not typically lead to these negative effects ${ }^{25)}$. To justify the safe use of chlorhexidine gluconate for dental restorative treatments, further studies are needed to analyze the beneficial and harmful effects of using chlorhexidine gluconate solutions with dental adhesive systems, and the influence of chlorhexidine gluconate application on bonding stability over time.

Saliva is $99.4 \%$ water, and the remaining composition comprises macromolecules (such as proteins, glycoprotein sugars, and amylase), inorganic particles (such as urea, amino acids, fatty acids, and

In Group 3, the dentin surfaces of specimens were 
free glucose), bacteria, and food debris. After saliva contamination, non-covalent adsorption of salivary protein occurs on the surfaces of both the tooth and restorative material, creating an organic coating that cannot be removed by rinsing with tap water ${ }^{17)}$. In the present study, salivary contamination (Group 4) was found to significantly decrease the tensile bond strength between dentin and ceramic, hence agreeing with the results of other reports ${ }^{14,17,26)}$. Webster et $a l^{27)}$ found that when saliva contamination occurred after applying a primer to dentin, reapplication of the primer after drying the saliva provided a good bond to the underlying primer layer. In addition, Eiriksson et al. ${ }^{26}$ ) reported that drying the saliva quickly resulted in a significantly stronger bond than drying the saliva slowly, which was probably due to reduced saliva film thickness. In the present study, SEM observation of saliva contamination revealed a smooth surface on the specimens, which seemed to suggest that reduced bond strength was probably due to a lack of interaction of the resin increment with the contaminated dentin surface (Fig. 4).

Prior to the placement of restorations in a clinical setting, there is a relatively high risk of blood contamination on the adherent dentin surface, especially for crown margins in the gingival area ${ }^{28)}$. In the present study, the blood-contaminated specimens were rinsed, but there remained a significant difference between the blood contamination group (Group 5) and the control group. Blood dried on the dentin surface caused a catastrophic decrease in bond strength at ceramic-resin interface, which was in agreement with published results ${ }^{28,29,30)}$. SEM observation (Fig. 5) revealed a smooth surface on the specimens when compared to the other surface treatments (Figs. 1, 2, 3, and 6), and which probably resulted in reduced bond strength due to the lack of interaction of the adhesive resin with the contaminated surface.

Adhesive systems are sensitive to saliva and blood contamination. This is attributable to the depositing of macromolecules of these contaminants into the dentinal tubules. In particular, blood contamination could reduce adhesive-dentin bond strength to a greater degree than salivary contamination, as its high protein content and macromolecules such as fibrinogen and platelets create a thin film on the dentin surface which hinders adhesive penetration into dentinal tubules ${ }^{31}$.

Hydrogen peroxide is one of the most common disinfectants and coagulant materials used in dentistry $^{32)}$. In this study, the tensile bond strength value of Group 6 (hydrogen peroxide) was statistically lower than the control group, which was in agreement with that of a previous study ${ }^{33)}$. It was probable that hydrogen peroxide which remained on the dentin surface altered surface morphology, causing a reduction in dentin-adhesive bond strength. Moreover, hydrogen peroxide decomposes into water and oxygen, with the latter penetrating rapidly through the porosities of dentin organic matrix, thereby exerting its detrimental effects $^{32)}$.
To compare the results of studies which have investigated contamination in adhesive restorations is a complex undertaking. Differences in the types of adhesive system, contamination period, substrate, and blood type reflect and underline a lack of methodological standardization. In addition, blood, salivary, and gingival fluid contamination typically occur concomitantly ${ }^{31)}$.

\section{CONCLUSION}

Within the limitations of this in vitro study, this paper concluded that saliva contamination, blood contamination, and hydrogen peroxide application influenced the tensile bond strengths of adhesiveceramic and adhesive-dentin interfaces, whereas no such detrimental effect was observed with Clinpro White Varnish and chlorhexidine gluconate applications.

\section{ACKNOWLEDGMENTS}

This study was supported in part by a grant for "Health Sciences Research Group" from The Scientific and Technological Research Council of Turkey (Project No: 107S146).

\section{REFERENCES}

1) Sjogren G, Lantto R, Granberg A, Sundstrom BO, Tillberg A. Clinical examination of leucite-reinforced glass-ceramic crowns (Empress) in general practice: a retrospective study. Int J Prosthodont 1999; 12: 122-128.

2) Frankenberger R, Petschelt A, Kramer N. Leucitereinforced glass ceramic inlays and onlays after six years: clinical behavior. Oper Dent 2000; 25: 459-465.

3) Fradeani M, D’Amelio M, Redemagni M, Corrado M. Fiveyear follow-up with Procera all-ceramic crowns. Quintessence Int 2005; 36: 105-113.

4) Wolfart S, Bohlsen F, Wegner SM, Kern M. A preliminary prospective evaluation of all-ceramic crown-retained and inlay-retained fixed partial dentures. Int J Prosthodont 2005; 18: 497-505.

5) Heather J Conrad, Wook-Jin Seong, Igor J Pesun. Current ceramic materials and systems with clinical recommendations. J Prosthet Dent 2007; 98: 389-404.

6) Nagai T, Kawamoto Y, Kakehashi Y, Matsumura H. Adhesive bonding of a lithium disilicate ceramic material with resin-based luting agents. J Oral Rehabil 2005; 32 : 598-605.

7) Stewart GP, Jain P, Hodges J. Shear bond strength of resin cements to both ceramic and dentin. J Prosthet Dent 2002; 88: $277-284$.

8) Kato H, Matsumura H, Ide T, Atsuta M. Improved bonding of adhesive resin to sintered porcelain with the combination of acid etching and a two-liquid silane conditioner. J Oral Rehabil 2001; 28: 102-108.

9) Kim BK, Bae HE, Shim JS, Lee KW. The influence of ceramic surface treatments on the tensile bond strength of composite resin to all-ceramic coping materials. J Prosthet Dent 2005; 94: 357-362.

10) Soeno K, Taira Y, Matsumura H, Atsuta M. Effect of desensitizers on bond strength of adhesive luting agents to dentin. J Oral Rehabil 2001; 28: 1122-1128.

11) Sung EC, Tai ET, Chen T, Caputo AA. Effect of irrigation 
solutions on dentin bonding agents and restorative shear bond strength. J Prosthet Dent 2002; 87: 628-632.

12) Susin AH, Vasconcellos WA, Saad JR, Oliveira Junior OB. Tensile bond strength of self-etching versus total-etching adhesive systems under different dentinal substrate conditions. Pesqui Odontol Bras 2007; 21: 81-86.

13) Soares CJ, Pereira CA, Pereira JC, Santana FR, do Prado CJ. Effect of chlorhexidine application on microtensile bond strength to dentin. Oper Dent 2008; 33: 183-188.

14) Oztoprak MO, Isik F, Sayinsu K, Arun T, Aydemir B. Effect of blood and saliva contamination on shear bond strength of brackets bonded with 4 adhesives. Am J Orthod Dentofacial Orthop 2007; 131: 238-242.

15) Ergun G, Cekic I, Lassila LV, Vallittu PK. Bonding of lithium-disilicate ceramic to enamel and dentin using orthotropic fiber-reinforced composite at the interface. Acta Odontol Scand 2006; 64: 293-299.

16) Cal E, Turkun LS, Turkun M, Toman M, Toksavul S. Effect of an antibacterial adhesive on the bond strength of three different luting resin composites. J Dent 2006; 34: 372-380.

17) Yang B, Lange-Jansen HC, Scharnberg M, Wolfart S, Ludwig K, Adelung R, Kern M. Influence of saliva contamination on zirconia ceramic bonding. Dent Mater 2008; 24: 508-513.

18) Tulunoglu IF, Oktemer M. Tensile strength and microleakage of the bond between a nickel-chromium alloy and a visible light-cured resin composite: effect of 4-META, silicoating, and bead retention. Quintessence Int 1997; 28: 447-451.

19) Kourtis SG. Bond strengths of resin-to-metal bonding systems. J Prosthet Dent 1997; 78: 136-145.

20) Aranha AC, Siqueira Junior Ade S, Cavalcante LM, Pimenta LA, Marchi GM. Microtensile bond strengths of composite to dentin treated with desensitizer products. J Adhes Dent 2006; 8: 85-90.

21) Seara SF, Erthal BS, Ribeiro M, Kroll L, Pereira GD. The influence of a dentin desensitizer on the microtensile bond strength of two bonding systems. Oper Dent 2002; 27: 154160.

22) Pappas M, Burns DR, Moon PC, Coffey JP. Influence of a 3 -step tooth disinfection procedure on dentin bond strength.
J Prosthet Dent 2005; 93: 545-550.

23) Carrilho MR, Carvalho RM, de Goes MF, di Hipólito V, Geraldeli S, Tay FR, Pashley DH, Tjäderhane L. Chlorhexidine preserves dentin bond in vitro. J Dent Res 2007; 86: 90-94.

24) de Castro FL, de Andrade MF, Duarte Júnior SL, Vaz LG, Ahid FJ. Effect of $2 \%$ chlorhexidine on microtensile bond strength of composite to dentin. J Adhes Dent 2003; 5: 129138.

25) Perdigao J, Denehy GE, Swift EJ Jr. Effects of chlorhexidine on dentin surfaces and shear bond strengths. Am J Dent 1994; 7: 81-84.

26) Eiriksson SO, Pereira PN, Swift EJ Jr, Heymann HO, Sigurdsson A. Effects of saliva contamination on resin-resin bond strength. Dent Mater 2004; 20: 37-44.

27) Webster MJ, Nanda RS, Duncanson MG Jr, Khajotia SS, Sinha PK. The effect of saliva on shear bond strengths of hydrophilic bonding systems. Am J Orthod Dentofacial Orthop 2001; 119: 54-58.

28) Kaneshima T, Yatani H, Kasai T, Watanabe EK, Yamashita A. The influence of blood contamination on bond strengths between dentin and an adhesive resin cement. Oper Dent 2000; 25: 195-201.

29) Xie J, Powers JM, McGuckin RS. In vitro bond strength of two adhesives to enamel and dentin under normal and contaminated conditions. Dent Mater 1993; 9: 295-299.

30) Abdalla AI, Davidson CL. Bonding efficiency and interfacial morphology of one-bottle adhesives to contaminated dentin surfaces. Am J Dent 1998; 11: 281-285.

31) Raffaini MS, Gomes-Silva JM, Torres-Mantovani CP, Palma-Dibb RG, Borsatto MC. Effect of blood contamination on the shear bond strength at resin/dentin interface in primary teeth. Am J Dent 2008; 21: 159-162.

32) Barbosa CM, Sasaki RT, Florio FM, Basting RT. Influence of time on bond strength after bleaching with $35 \%$ hydrogen peroxide. J Contemp Dent Pract 2008; 9: 81-88.

33) Perdigao J, Francci C, Swift EJ Jr, Ambrose WW, Lopes M. Ultra-morphological study of the interaction of dental adhesives with carbamide peroxide-bleached enamel. Am J Dent 1998; 11: 291-301. 